\title{
Design and Evaluation of a Web-based Virtual Open Laboratory Teaching Assistant (VOLTA) for Circuits Laboratory
}

\section{Mr. Firdous Saleheen, Temple University}

Firdous Saleheen received the B.Sc. degree in electrical and electronic engineering from Bangladesh University of Engineering and Technology (BUET), Dhaka, Bangladesh, in 2008, and the M.S. degree in electrical engineering from Temple University, Philadelphia, PA, USA in 2013. From 2008 to 2010, he was with Mango Teleservices Ltd., Dhaka, an international IP bandwidth provider of Bangladesh, as a Senior Engineer in the Research and Development Department. He is currently pursuing the Ph.D. degree in electrical engineering in ECE department of Temple University. His research interests include tactile sensation imaging, diffuse optical imaging, biomedical imaging systems development, machine learning, and statistical control theory.

\section{Mr. Salvatore Giorgi, Temple University}

Salvatore Giorgi received his Bachelor's and Master's degree in Electrical Engineering at Temple University in 2012 and 2014, respectively. His research interest includes optimal cost density shaping, statistical control and adaptive neural control.

\section{Mr. Zachary Thomas Smith, Temple University \\ Dr. Joseph Picone, Temple University}

Joseph Picone received his Ph.D. in Electrical Engineering in 1983 from the Illinois Institute of Technology. He is currently a Professor in the Department of Electrical and Computer Engineering at Temple University. His primary research interests are currently machine learning approaches to acoustic modeling in speech recognition. His research group is known for producing many innovative open source materials for signal processing including a public domain speech recognition system. He is a Senior Member of the IEEE and has been active in several professional societies related to human language technology. He has authored numerous papers on the subject and holds several patents in this field.

\section{Dr. Chang-Hee Won, Temple University}

Chang-Hee Won is an associate professor of electrical and computer engineering in the Department of Electrical and Computer Engineering and the director of Control, Sensor, Network, and Perception (CSNAP) Laboratory at Temple University. Previous to coming to academia, he worked at Electronics and Telecommunications Research Institute as a senior research engineer. Currently, he is actively guiding various research projects funded by National Science Foundation, Pennsylvania Department of Health, and Department of Defense. His research interests include stochastic optimal control theory, sensing systems, and virtual laboratory assistant. 


\title{
Design and Evaluation of a Web-based Virtual Open Laboratory Teaching Assistant (VOLTA) for Circuits Laboratory
}

\author{
Firdous Saleheen, Salvatore Giorgi, Zachary Smith, Joseph Picone and Chang-Hee Won \\ Department of Electrical and Computer Engineering
}

Temple University

\begin{abstract}
A Virtual Open Laboratory Teaching Assistant (VOLTA) provides personalized instruction for students participating in a self-paced undergraduate circuits laboratory. VOLTA allows students to work in the open laboratory even when a teaching assistant is unavailable. The system's components include pre-lab testing and instruction, engineering design exercises, short topic explanation videos, instrumentation instruction (including safety), and a corresponding post-lab test module. This web-based software guides a student through a circuit simulation and hardware laboratory. VOLTA will also answer frequently asked questions that the student might have during the lab. Furthermore, VOLTA can guide the students in building, verifying, and troubleshooting a circuit simulation by utilizing a circuit recognition algorithm. This algorithm uses image processing to recognize the simulated circuits. Preliminary results show the circuit recognizer module can identify simple RLC circuits. This virtual open lab approach requires fewer resources and adds flexibility by using fewer teaching assistants and less dedicated laboratory spaces. The merits of our open laboratory approach include (1) individual, self-paced learning, (2) 24/7 accessibility, (3) personalized instructions for shy or more timid students in a non-threatening environment, and (4) increasing level of engagement. Because of these advantages, students who learn in an open lab environment will perform better than in a traditional closed lab. In this paper, we present the VOLTA software framework and discuss the preliminary results of pre- and post-lab assessment. The ANOVA test on pre-test and post-test scores showed a $p$-value of 0.171 indicating a modest improvement in performance compared to students who took the same course taught using a traditional closed laboratory approach. This study suggests that VOLTA can be used as an effective learning tool in circuits' laboratories.
\end{abstract}

\section{Introduction}

Laboratories have always been an integral part of the engineering education, where engineering concepts were reinforced by hands-on experience in laboratory experiments. Traditional on-site experiment-based laboratories have several limitations, such as expensive laboratory resources, limited space, schedule conflicts and short term exposure. Therefore, it is necessary to find alternative methods for enhancing the engineering laboratory experience. ${ }^{1,2}$. 
Over the past few decades, interesting laboratories have been developed in different branches of engineering such as controls ${ }^{3}$, process engineering ${ }^{4}$, nanotechnology ${ }^{5}$, and chemical engineering ${ }^{6}$. Moreover, other approaches have been explored such as, virtual laboratories ${ }^{7}$, table-based laboratories ${ }^{8}$, and remote laboratories ${ }^{9}$. In a traditional "closed laboratory" environment, students perform the assignments following a "cook-book" lab manual and submit a written report drafted after the laboratory has been completed. It is argued that this is the not format most conducive to learning ${ }^{10}$. Space constraints are mitigated by dividing the students into multiple sections. In each section, the students are grouped in a team because of equipment shortages. Sometimes, scheduling constraints force a lab to be performed out of sequence with the lecture. Because of time constraints, students receive a less-than-ideal exposure to the concepts and the associated instrumentation.

A better alternative can be an open laboratory where the students can return to repeat and refine their experiments. Palais and Javurek defined the open laboratory as "a single large room containing equipment for performing experiments associated with all the electrical engineering undergraduate laboratories" $" 11$. The popularity of the open laboratory lies in its ability to maximize resource utilization. Lab scheduling becomes more flexible, teaming is enhanced, and equipment is more effectively utilized in an open laboratory ${ }^{12}$. However, this requires self-paced labs that can be completed without direct supervision. Our goal is to transform traditional laboratories to open laboratories for basic electrical engineering courses such as circuits. By "open laboratory" we mean a physical laboratory where students can perform their laboratory assignments at their own convenience.

In a traditional laboratory approach, teaching assistants help the students with assembly and debugging. Students can also receive individual instruction from graduate student teaching assistants (TAs) during office hours. It is very difficult to deliver on-demand, asynchronous help for large populations of students with a limited number of TAs. In order to mitigate the availability issue of teaching staff, we proposed a framework that can provide "virtual teaching assistance" to the students. This framework is called the "Virtual Open Laboratory Teaching Assistant (VOLTA)". Equipped with pre-lab testing and instruction, engineering design exercises, short topic explanation videos, instrumentation instruction (including safety), and a corresponding post-lab test module, VOLTA is able to provide asynchronous, on demand, and smart assistance to the students. In this paper, we present the VOLTA framework, VOLTA's adaptation in a circuit course, and a primary assessment of its application to an entry-level circuit course.

The paper is organized as follows: Section 2 is an overview of VOLTA design, Section 3 describes the assessment methods for VOLTA, and Section 4 presents the assessment results. Finally, conclusions are presented in the last section. 


\section{VOLTA Design Overview}

In this section, we describe the overview of VOLTA. We start with a brief description of the physical architecture and discuss different modules in VOLTA framework.

The Virtual Open Lab Teaching Assistant (VOLTA) is a system which can guide a student to perform hardware electrical engineering circuits' laboratory 24 hours/7days without any human teaching assistant. Figure 1 shows the physical architecture of VOLTA. The different modules of VOLTA, hosted in a server, are accessible via internet for the instructors, developers, and students. The students have a portable and compact hardware for circuit implementation. VOLTA is preloaded with instructional videos, definitions, and explanations. It supports ondemand learning and provides immediate feedback on laboratory exercises and exams. For instructors, it provides an administration panel that supports management of the laboratory content.

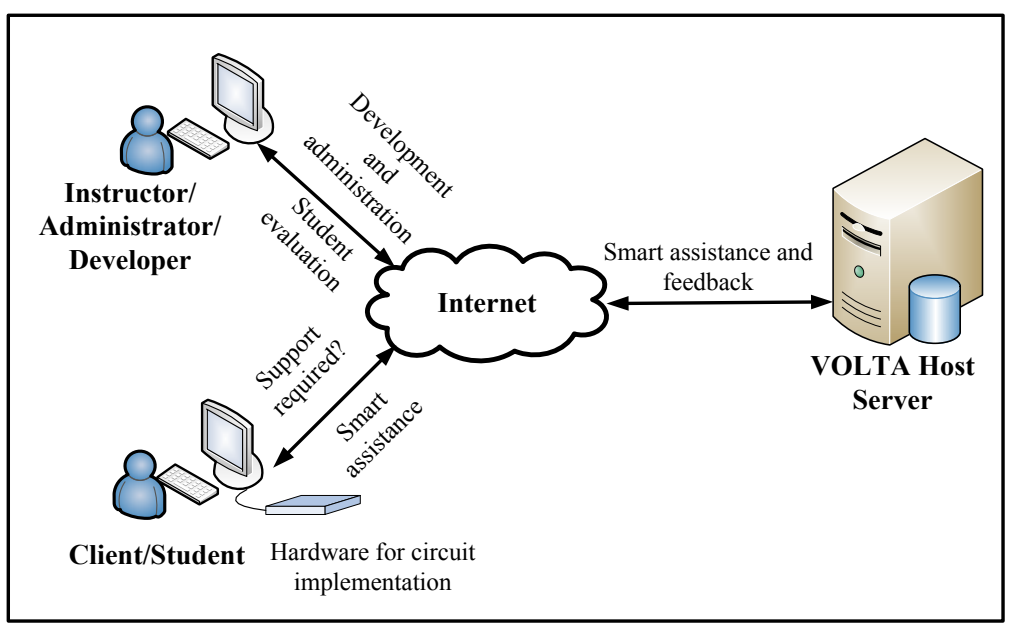

Figure 1: Physical architecture of VOLTA

\section{VOLTA Framework}

The physical architecture of VOLTA is based on a framework as shown in Figure 2. The VOLTA consists of five modules and a database. The modules are (1) Instructor module, (2) Student module, (3) Help module, (4) Circuit recognizer module, and (5) Speech module. 


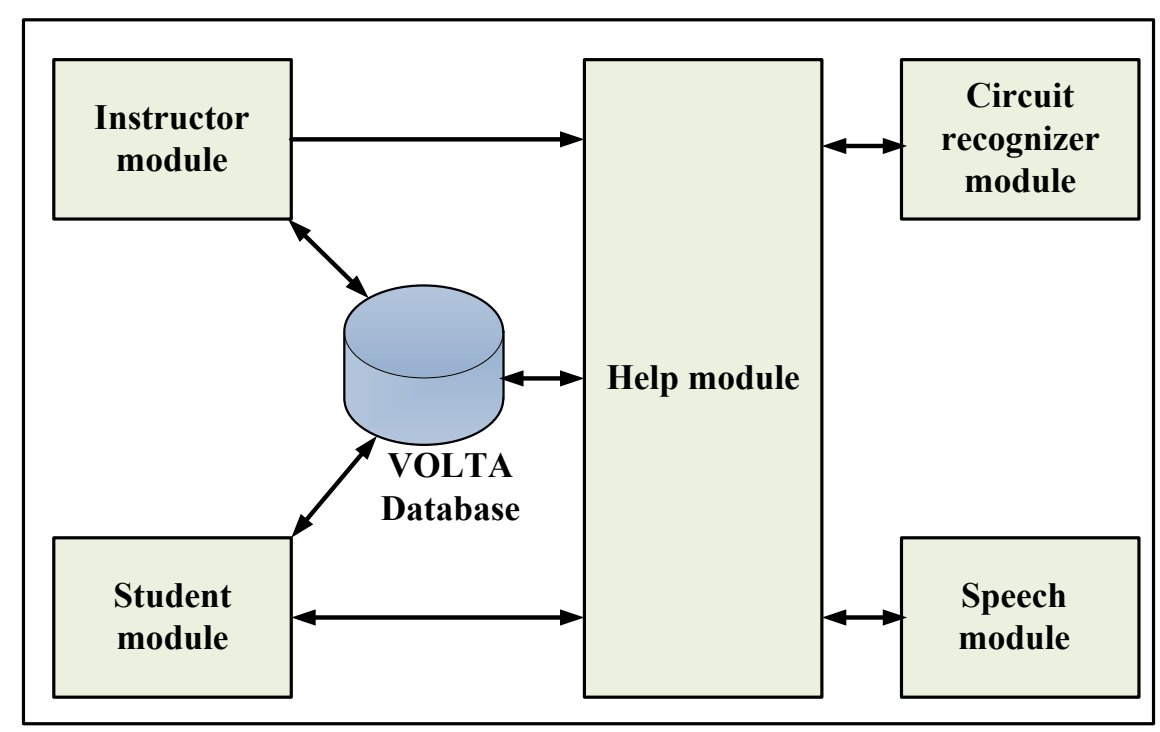

Figure 2: VOLTA framework

The instructor module is used to administer the VOLTA. The student module is a graphical user interface in web framework for the enrolled students. It works with the Help module for providing virtual assistance to the students. The Help module in conjunction with the Circuit recognizer module and the Speech module gives smart help and feedback to the students. The VOLTA is implemented using Python (version 2.7.1) and Django (version 1.6.5) ${ }^{13}$.

\section{Instructor module}

The instructor module provides a flexible environment for an instructor or teaching assistant to perform his/her tasks. Figure 3 shows the Instructor module which performs four major tasks. It authorizes the students for access into VOLTA through the student module. The instructor can update the lab contents via an administration panel. It also helps upload the supporting materials into database for the Help module.

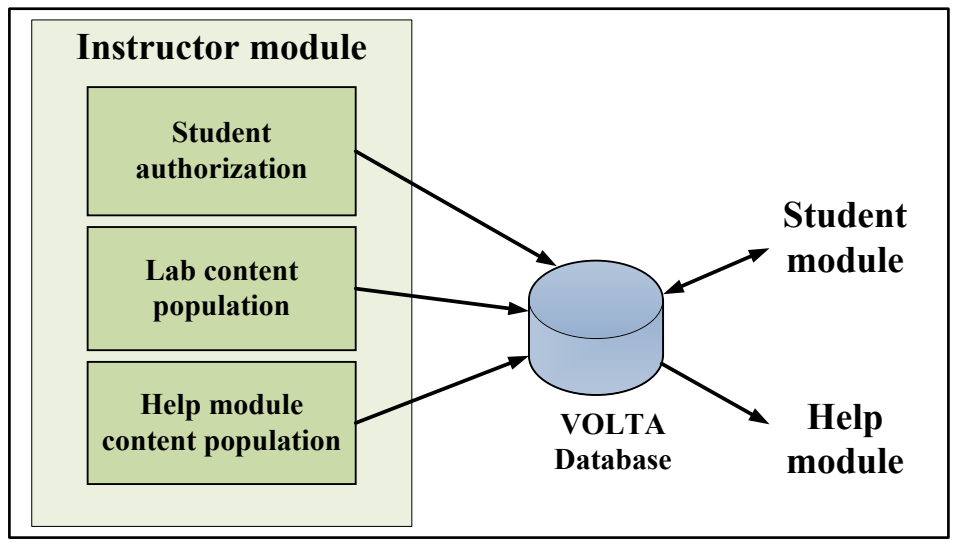

Figure 3: Instructor module 


\section{Student module}

The student module is the part of VOLTA that interacts with the students. Figure 4 shows the Student module diagram. It guides the students step-by-step for completing an experiment. It helps the student to understand the subject clearly through tests. It evaluates the student before and after the lab-work. It fetches 'smart' assistance from VOLTA Help module.

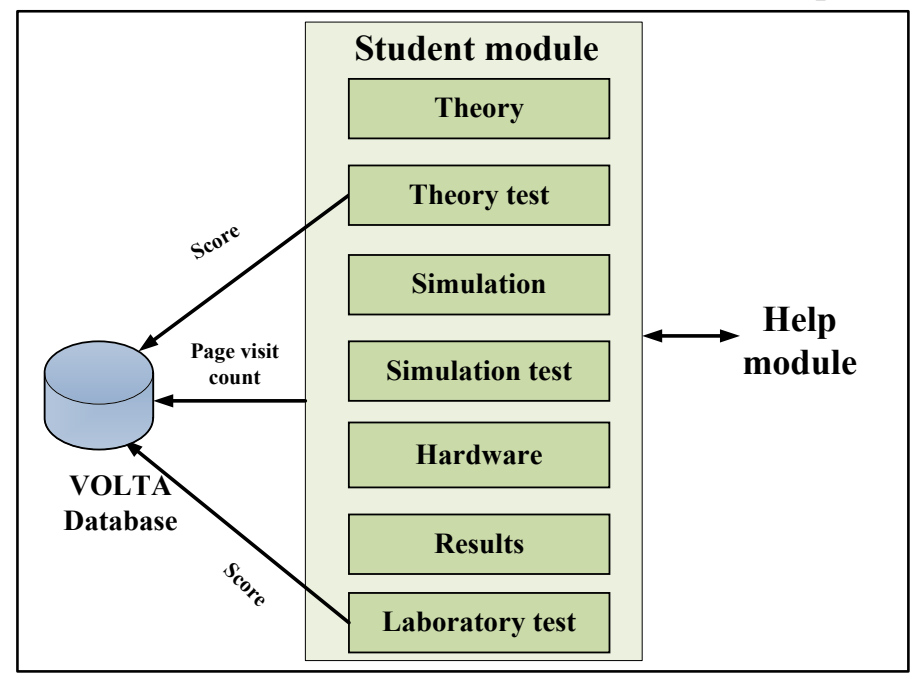

Figure 4: Student module

Students interact with VOLTA using the student module. This module guides students through an experiment step-by-step. It evaluates student progress using pre-tests and post-tests that consist of multiple choice questions. The same set of questions were asked in pre- and post-tests. In post-tests, the multiple choice options were not in the same order as in pre-tests. After the pretest, the students are directed to the simulation section. In this section, the students are instructed to simulate their circuits before constructing a hardware implementation.

The hardware section provides instructions for building circuit in the breadboard. The student uses Digilent EE (Electronics Explorer) board ${ }^{14}$ (Digilent Inc., Pullman, Washington, USA) for hardware implementation. The EE board is built around a solderless breadboard, which also includes oscilloscopes, waveform generators, power supplies, voltmeters, reference voltage generators, and thirty-two digital signals that can be configured as a logic analyzer, pattern generator, or any one of several static digital I/O devices. All of these instruments can be connected to circuits built on the solderless breadboards using simple jumper wires. For data acquisition and analysis, PC-based software named "WaveForms" is used. A high-speed USB 2.0 connection ensures near real time data acquisition. The Results section contains the guideline for the contents of report. Finally, the students take a laboratory which is a post-test in the form of multiple-choice based on the lab. Figure 5 shows the interface of VOLTA used by the students. 


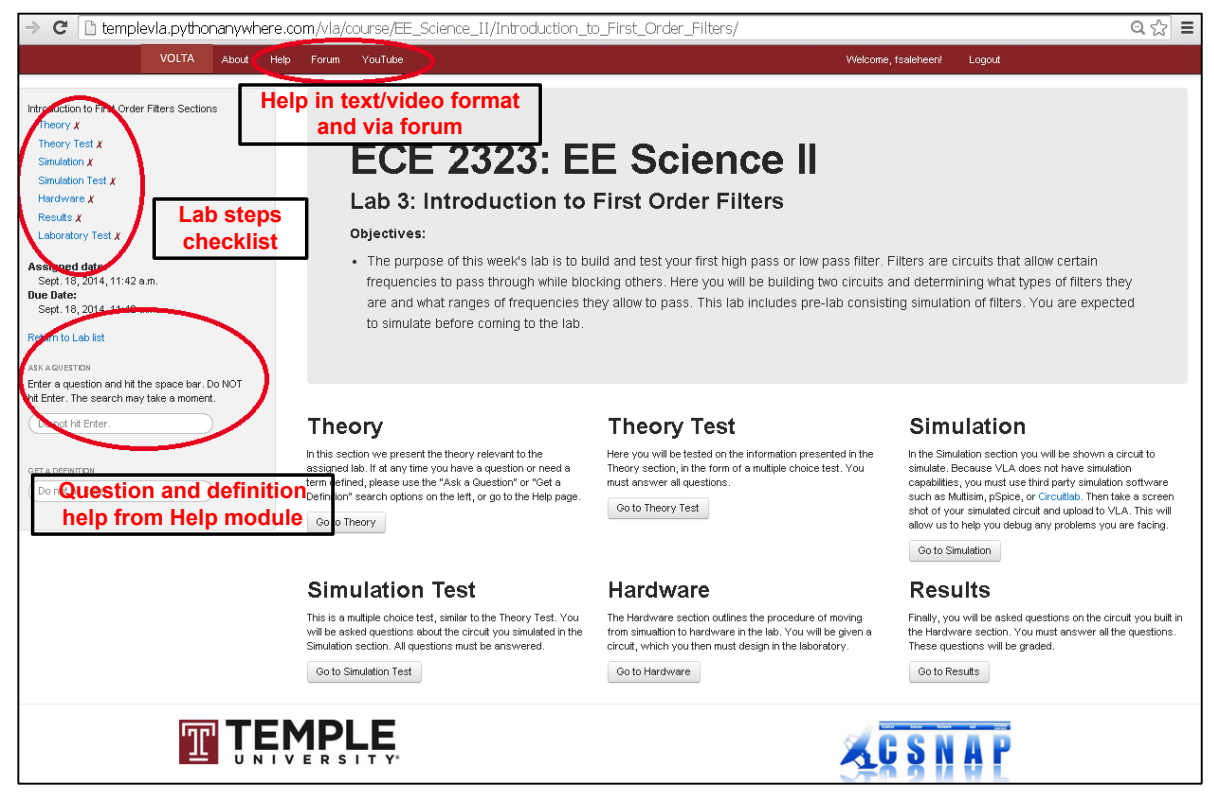

Figure 5: Student Interface of VOLTA

\section{Help module}

The Help module is one of the most important parts of VOLTA which is shown in Figure 6. This module provides the students with a teaching-assistance-like-service in virtual formats. The students can seek help from this module at any point of VOLTA session. This module provides multiple sub-modules consisting of definitions of circuit terminology, questions and answers about basic circuit and the related lab, safety video tutorial, basic instrument use video tutorial, forum for discussing the problems, and how-to-use VOLTA video tutorial. These sub-modules are pre-loaded with the necessary materials by the instructor. It works in conjunction with a circuit recognizer module and a speech module. The circuit recognizer helps the students verify and debug their circuits. The speech module gives options of voice-activated smart search capability.

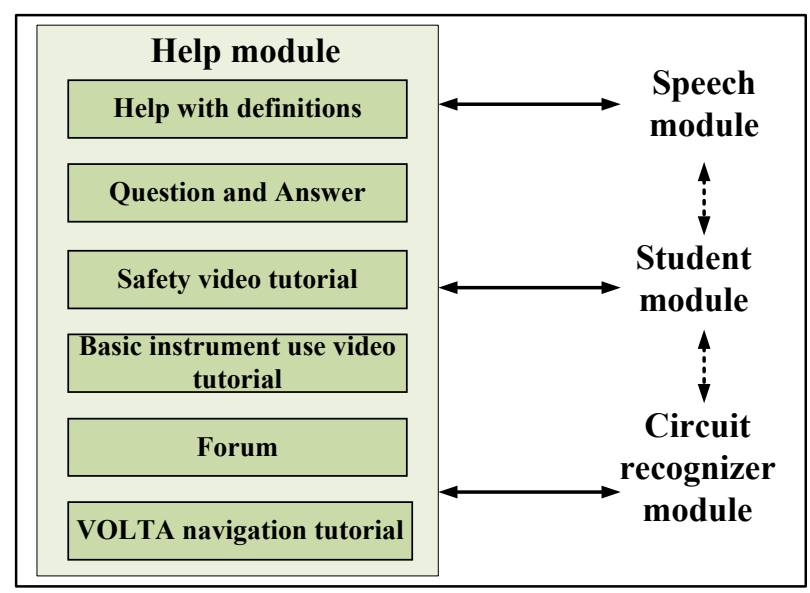

Figure 6: Help module 


\section{Circuit Recognizer module}

The circuit recognizer module is one of the salient features of VOLTA. It helps the students verify their simulated circuits and debug their hardware circuits. This module contains an image processing algorithm for automatic recognition of the circuit schematics. Figure 7 shows the flowchart for the circuit recognition process. The students upload their schematic for simulation in VOLTA. The schematic serves as the input to the module. The image processing performs background removal, contour filtering, and component recognition via template matching. Finally, the module outputs a schematic with labeled nodes, components with values, and a HTML formatted netlist (word description of the circuit). This module also helps debugging a hardware circuit by providing a trace-guide. A hardware circuit may not work properly for a few reasons, such as bad connections, bad components, incorrect wiring, bad instrument setting, and power problems. VOLTA can address the incorrect wiring problems by providing circuit trace help.

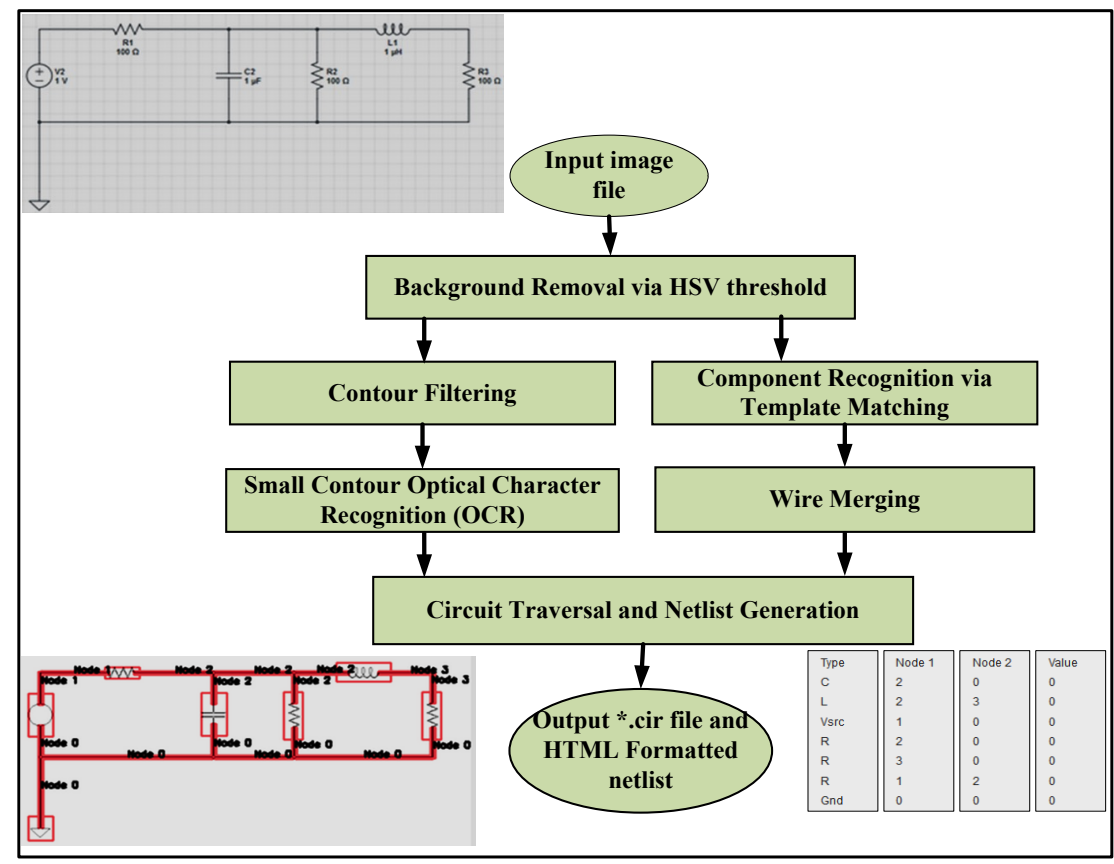

Figure 7: Circuit recognizer module

\section{Speech module}

The speech module provides a more flexible means for assisting the student. Figure 8 shows the speech module diagram. It can provide voice activated search in VOLTA. This module can offer help by detecting emotional state of the student. The input to the speech module is the speech signal generated from the student's voice. With permission, the speech module records the student's voice continuously during the VOLTA session. The speech signal is sent to a Google speech-to-text API server for speech-to-text conversion. The converted text is stored in the 
VOLTA host server. If a keyword 'HELP' is detected, it writes the next string after HELP into VOLTA Help module search box. For example, "HELP resistor" will write "resistor" in the search box, and pull the resistor related information. Speech module defines a few emotional states based on the word/phrases. If those strings of word/phrases are detected, the emotional states of the students (for example, frustration) are determined, and the VOLTA then offers help with strings such as "Do you need help?"

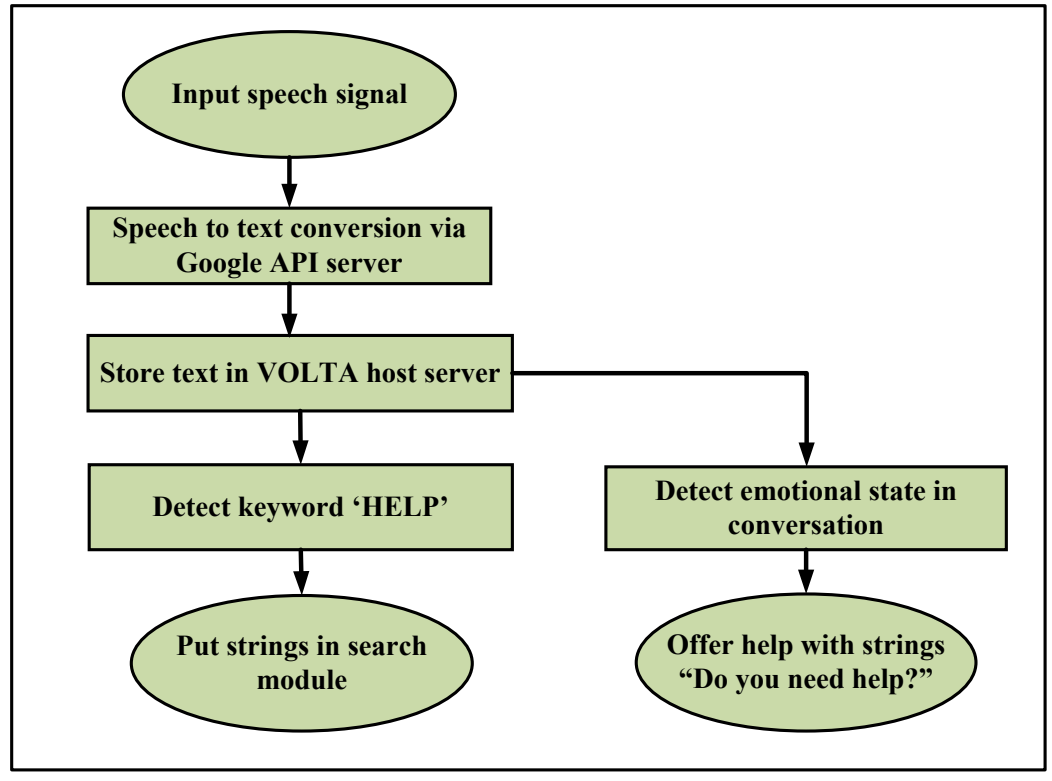

Figure 8: Speech module

\section{Assessment Methods of VOLTA}

The VOLTA was evaluated from two perspectives: usability and effectiveness. Usability evaluation data provides knowledge about a program's functional effectiveness, efficiency, ease of learning, ease of use, motivational influence, and quality assurance. On the other hand, the effectiveness study of VOLTA provides insights about its usefulness compared to traditionally taught classes. We obtained IRB approval from Temple University (Protocol number is 22447).

\section{Usability}

The survey includes 20 questions using a 5-point Likert scale (where $1=$ strongly disagree and 5 $=$ strongly agree) and 3 open-ended questions. Twenty questions were asked covering seven broad categories:

A. Did the students think the VOLTA is useful for their learning? (Learning environment)

B. Did the students find the software motivating? (Motivational value)

C. Did the students find the VOLTA easy to use? (Ease of use) 
D. Did the students perceive the usefulness of various features of the VOLTA? (Perception of usefulness)

E. Did the students "buy into" the virtual laboratory environment? (Authenticity of virtual learning)

F. What was the perceived quality of the VOLTA? (Quality assurance)

G. What additional features or learning situation the students would like to see in the VOLTA? (Expectations)

\section{Effectiveness}

The study involves the students enrolled in a course on circuits. The course had two sections. The students were randomly assigned to each section. The sections were randomly chosen as experimental and control groups. The students in the experimental group received a curriculum in which the instructor integrated the VOLTA. The students in the control group received the traditional course curriculum. The effectiveness of the VOLTA is assessed using gain score analysis of pre-test/post-test design ${ }^{15}$.

\section{Course Topics}

Eleven lab assignments were developed to use to with VOLTA. The lab assignments were as follows:

i. Introduction to Multisim using RC circuit,

ii. Introduction to Digilent board using RC circuit,

iii. Introduction to first order filters,

iv. Step response of a second order filter,

v. Frequency response of a second order filter,

vi. Design of second order circuit based on step response,

vii. Impedance measurement of $\mathrm{AC}$ circuit,

viii. Bass booster implementation using active filters,

ix. Gain bandwidth product and slew rate of op-amp,

$\mathrm{x}$. Introduction to boost converter, and

xi. Introduction to amplitude modulation.

\section{Assessment Results of VOLTA}

\section{Usability}

In this study, the usability evaluation involved participation of the students and the data were collected through student survey. During Fall 2014, the usability data were collected from sixteen students in a single group design. These students were enrolled in an introductory AC circuit lab "EE Science II". They volunteered to use the VOLTA and complete the survey questionnaire. 
In category A, five Likert type questions were asked to understand how successful VOLTA was as a learning environment. At least $56 \%$ of the students agreed that they viewed the VOLTA as a useful learning tool. In category B, two questions were asked to assess the motivational value of VOLTA. At least $44 \%$ of the students agreed that they enjoyed using the VOLTA. In category C, three questions were asked regarding the ease of use of the VOLTA. $63 \%$ of the students found the VOLTA easy to use and $91 \%$ found it easy to navigate. However, the students felt that the use of the VOLTA was less intuitive (44\%). In category D, four questions were asked regarding what degree the VOLTA's features were helpful. 44\% students found the Help module useful, $69 \%$ students thought VOLTA Youtube channel was useful, 50\% found the VOLTA as lab results verification tool, and 19\% found forum feature of the VOLTA useful. The students indicated that the instructional videos were the most helpful features of the VOLTA. In category E, two questions were asked regarding the authenticity of virtual learning. 50\% students felt the labs seemed like a real lab. 37\% students felt as if the teaching assistant were helping in the labs directly. In category F, two questions were asked to assess the quality of the videos and the VOLTA overall. In both cases, $69 \%$ students agreed the videos were of good quality and the VOLTA was trouble-free. In category G, two questions were asked about the expectations from the VOLTA. $81 \%$ students expected a feature to verify their simulation results in the VOLTA. $69 \%$ students expected a feature in VOLTA to ask the human teaching assistants about lab related questions.

\section{Effectiveness}

A total of 34 students participated in this study. The experimental group consisted of 16 students, while the control group consisted of 18 students. The experimental and control groups were taught on different day and time of the week. A total of eleven lab assignments were performed in eleven weeks. In each of the lab assignment, there were a pre-lab test and a post-lab test. The pre-lab test comprised five questions in multiple choice formats. Each question carried 20 points. The post-lab test comprised the same five questions with the multiple choices in different order. The same instructor taught both sections. Table 1 and 2 show the pre-test post-test scores of the control and experimental group of students, respectively. The average gain is the difference between the mean post- and pre-test score. 
Table 1: Control Group's ( $\mathrm{n}=18)$ Pre-test and Post test Score

\begin{tabular}{|c|c|c|c|c|c|}
\hline \multirow{2}{*}{$\begin{array}{c}\text { Lab } \\
\text { Assignment } \\
\text { no. }\end{array}$} & \multicolumn{2}{|r|}{ Pre-test } & \multicolumn{2}{|r|}{ Post-test } & \multirow{2}{*}{$\begin{array}{r}\text { Average } \\
\text { gain }\end{array}$} \\
\hline & Mean & Standard Deviation & Mean & Standard Deviation & \\
\hline 1 & 64.44 & 15.71 & 66.67 & 20.00 & 2.23 \\
\hline 2 & 36.67 & 17.95 & 47.78 & 19.02 & 11.11 \\
\hline 3 & 64.21 & 27.97 & 62.22 & 33.26 & -1.99 \\
\hline 4 & 51.76 & 13.82 & 48.24 & 22.81 & -3.52 \\
\hline 5 & 83.33 & 24.27 & 90.00 & 15.28 & 6.67 \\
\hline 6 & 68.75 & 27.36 & 82.67 & 17.69 & 13.92 \\
\hline 7 & 76.67 & 24.27 & 72.94 & 28.24 & -3.73 \\
\hline 8 & 76.00 & 23.32 & 82.67 & 17.69 & 6.67 \\
\hline 9 & 71.11 & 20.25 & 76.47 & 12.34 & 5.36 \\
\hline 10 & 52.50 & 26.34 & 65.00 & 27.84 & 12.50 \\
\hline 11 & 68.57 & 23.56 & 70.59 & 21.82 & 2.02 \\
\hline
\end{tabular}

Table 2: Experimental Group's $(n=16)$ Pre-test and Post test Score

\begin{tabular}{|c|c|c|c|c|c|}
\hline \multirow{2}{*}{$\begin{array}{c}\text { Lab } \\
\text { Assignment } \\
\text { no. }\end{array}$} & \multicolumn{2}{|r|}{ Pre-test } & \multicolumn{2}{|r|}{ Post-test } & \multirow{2}{*}{$\begin{array}{r}\text { Average } \\
\text { gain }\end{array}$} \\
\hline & Mean & Standard Deviation & Mean & Standard Deviation & \\
\hline 1 & 58.89 & 22.58 & 71.11 & 23.31 & 12.22 \\
\hline 2 & 47.14 & 17.90 & 40.01 & 18.52 & -7.13 \\
\hline 3 & 58.75 & 23.95 & 57.50 & 21.70 & -1.25 \\
\hline 4 & 68.57 & 26.95 & 65.00 & 24.66 & -3.57 \\
\hline 5 & 68.57 & 26.95 & 74.29 & 23.21 & 5.72 \\
\hline 6 & 61.54 & 27.69 & 64.62 & 28.45 & 3.08 \\
\hline 7 & 66.67 & 18.9 & 68.00 & 20.40 & 1.33 \\
\hline 8 & 86.67 & 13.98 & 93.33 & 11.93 & 6.66 \\
\hline 9 & 63.08 & 15.38 & 84.62 & 11.51 & 21.54 \\
\hline 10 & 65.45 & 21.05 & 76.36 & 20.57 & 10.91 \\
\hline 11 & 74.29 & 26.65 & 87.14 & 17.90 & 12.85 \\
\hline
\end{tabular}



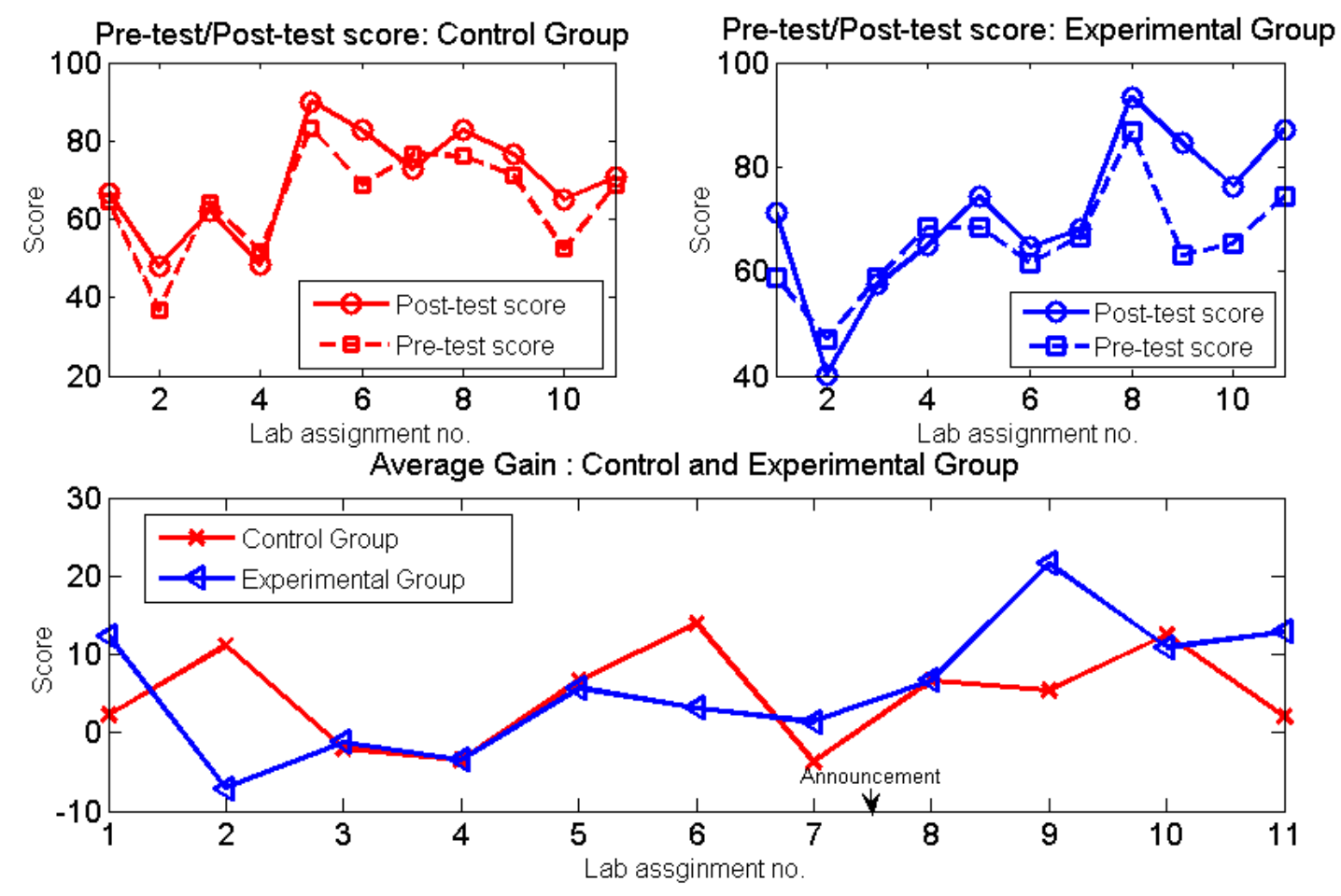

Figure 9: Pre-test and Post-test score

Figure 9 shows pre-test and post-test score versus lab assignment index and average gain versus lab assignment index plot. From the figure, we see that students taught by VOLTA performed significantly better in lab assignments $1,7,9$, and 11 , whereas traditionally taught students scored significantly better in lab assignments 2 and 6 . The rest of lab assignments showed a little difference.

A two-group pre-test/post-test design approach was used to evaluate the effectiveness of the VOLTA. The major question guiding the evaluation of the VOLTA's effectiveness on learning: Did the students who used the VOLTA (experimental group) learn more (e.g. score higher on gain measures) than their counterparts in the control group? The gain score analysis approach were used analyze data from the two-group pre-test/post-test research design. The gain score is defined as the difference between the post-test and pre-test score. The null hypothesis is that there is no difference among the mean gains of the experimental and control groups for eleven assignments. We performed ANOVA test ${ }^{16}$ on the gain scores of 34 students in 11 lab assignments. The ANOVA test was performed using R (version 3.1.2). The ANOVA $p$-value was 0.17 indicating that the null hypothesis cannot be rejected if we consider a significance level of 0.05 ( $95 \%$ confidence interval). In other words, there is not sufficient evidence that the students taught by VOLTA performed better than their counterparts in the traditional labs. Our results are significant at an $80 \%$ level of confidence, which implies students who had access to VOLTA performed significantly better than their counterparts in the traditional labs. 
During the course of the experiment, students were not told that the post-test grades will be used in their lab grade. Not surprisingly, they assumed that the pre- and post-test grades did not matter. We wanted to test the effect of an announcement that the post-test grade would be counted towards the final grade. So, before Lab 8, the experiment group was informed that the lab post-test results would be counted towards the calculation of their final grades. Considering the announcement as a factor, we tested its effect on the students' gain score. The null hypothesis of test is that there is no difference among the mean gain score of the students for eleven lab assignments due to announcement. The ANOVA test results showed a $p$-value of 0.0117 (smaller than the significance level 0.05), which indicates that there is sufficient evidence that this announcement has significant effect on the students' gain score.

\section{Conclusions}

VOLTA is a framework for providing the students with an open laboratory environment equipped with virtual teaching assistance. Compared to traditional closed laboratories, VOLTA provides a self-paced environment, on-demand help, and an increasing level of engagement. We received positive feedback from the students on various VOLTA contents such as instructional videos, safety videos, short topic and explanations. The primary assessment shows a modest improvement on students' performance in the class conducted by VOLTA, with the $p$-value of 0.171 . When we announced that the post-test grades will count towards the laboratory grade the $p$-value became 0.0117 , which means that there were significance increases from the pre-test to post-test grades. We are repeating the experiment in the Spring 2015 semester using a more advanced version of VOLTA that includes a functional circuit recognizer, hardware assembly instructions, and a richer help module. The circuit recognizer will verify the students' simulated circuit. The hardware assembly instructions will be generated according to the multisim netlist. The help module is loaded with revised information about lab assignments. These enhancements are designed to decrease user frustration thereby enhancing the user experience.

\section{Acknowledgement}

This work was supported by a grant from the National Science Foundation grant number DUE 1245277. This work was partially done under the Temple University College of Engineering Summer Undergraduate Research Program. We thank Dr. Richard Heiberger, Professor Emeritus of Statistics department for his contribution in data analysis. We are grateful to Dr. Brian Butz, Professor Emeritus of ECE department in Temple University for his insightful remarks for the framework development. 


\section{Bibliography}

1. Ernst, E.W., “A New Role for the Undergraduate Engineering Laboratory,” IEEE Transactions on Education, Vol. E-26, No. 2, May 1983, pp. 49-51.

2. Middleton, N.T., and R.L.Branch, "Experiential engineering management in collaborative graduate undergraduate projects", Proceedings of the 1996 26th Annual Conference on Frontiers in Education, FIE'96, Part 3 (of 3), Nov 6-9, 1996.

3. Rubaai, Ahmed, "Laboratory Innovations in Undergraduate Control Engineering Education", 2010 ASEE Annual Conference \& Exposition, 2010.

4. Chaabene M, K. Mkaouar, and R Souissi. A Web-based Control of a Real Laboratory for Process Engineering Education. In World Automation Congress, Hungry, July 2006.

5. Sarangon, A., Haus, J., Jain, S., and Moradmand, J., "Collaborative Classroom Tools for Nanotechnology Process Education", $120^{\text {th }}$ ASEE Annual Conference \& Exposition, June, 2013.

6. Kelly, C., Gummer, E., and Harding, P., Koretsky, M., "Teaching Experimental Design Using Virtual Laboratories: Development, Implementation And Assessment Of The Virtual Bioreactor Laboratory”, 2008 ASEE Annual Conference \& Exposition, 2008.

7. Koretsky, M., Kelly, C., “Enhancement Of Student Learning In Experimental Design Using Virtual Laboratories”, 2010 ASEE Annual Conference \& Exposition, 2010.

8. Huettel, L., "Integration Of A DSP Hardware Based Laboratory Into An Introductory Signals And Systems Course", 2006 ASEE Annual Conference \& Exposition, 2006.

9. Rock, M. et al, "Effectively Utilizing Local Andremote Thermofluids Laboratory Experiments Toenhance Student Learning.", 2011 ASEE Annual Conference \& Exposition, 2011.

10. Knight, C. D. \& DeWeerth, S. P. , “A shared remote testing environment for engineering education”, Proceedings of the ASEE 1996 Annual Frontiers in Education Conference, Session 8c1, November 6-9, 1996, Salt Lake City, UT, USA, pp. 1003-1006.

11. Palais, J., and Javurek, C., "The Arizona State University Electrical Engineering Undergraduate Open Laboratory", IEEE Transactions on Education, Vol. 39, No. 2, May 1996.

12. Kuhn, W., Hummels, D., and Dyer, A., "A Senior-level RF Design Course Combining Traditional Lectures with an Open Laboratory Format", 30th ASEE/IEEE Frontiers in Education, October 18 - 21,2000 Kansas City, MO Conference

13. https://www.djangoproject.com/

14. https://www.digilentinc.com/data/Products/EEBOARD/Digilent-EEboard-np-07.pdf

15. Dimiter M. Dimitrov and Phillip D. Rumrill, Jr., "Pretest-posttest designs and measurement of change", IOS press, Work 20 (2003) 159-165.

16. Montgomery, D.C., "Design and Analysis of Experiments", John Wiley \& Sons, Incorporated, 2012. 
Appendix

ANOVA table for the students' gain score

ANOVA test is a statistical method of analyzing the differences between group means. ${ }^{13}$ In this method, the observed variance in a variable is decomposed into components attributable to various source of variation. For our experiment, we adopt completely randomized design approach. We randomly chose a section of students for two different treatments. Since the lab assignments are different each week, we considered the lab assignments as block variable, indicated by Lab assignment no. Teaching traditionally (control group) and by VOLTA (experimental group) were indicated by treatment variable Group. Table 3 shows the ANOVA results on gain score of 34 students. These results showed a $p$-value of 0.1714 (larger than 0.05 ), which indicates that the null hypothesis cannot be rejected. In other words, there is not sufficient evidence that the students taught by VOLTA performed better than their counterparts in the traditional labs.

Table 3: ANOVA results to test the effect of VOLTA on students' gain score

\begin{tabular}{lrrrrr}
\hline $\begin{array}{l}\text { Source of } \\
\text { Variation }\end{array}$ & $\begin{array}{c}\text { Degrees } \\
\text { of } \\
\text { freedom }\end{array}$ & $\begin{array}{c}\text { Sum of } \\
\text { Squares }\end{array}$ & $\begin{array}{c}\text { Mean } \\
\text { Square }\end{array}$ & F ratio & $p$-value \\
\hline Lab assignment no. & 10 & 7,654 & 765.4 & & \\
Group & 1 & 705 & 705.0 & 1.878 & 0.1714 \\
Residual & 362 & 135,907 & 375.4 & & \\
Total & 373 & 144,266 & & & \\
\hline
\end{tabular}

In order to test the effect of announcement that the post-test score would be counted toward the final grades, we performed the ANOVA test on the student gain score for eleven lab assignments. The announcement was made before Lab 8. Table 4 shows the ANOVA results. The $p$-value of this treat was smaller than 0.05 , which indicates that there is sufficient evidence that this announcement has significant effect on the students' gain score.

Table 4: ANOVA table to test the effect of announcement on students' gain score for eleven lab assignments

\begin{tabular}{lrrrrr}
\hline $\begin{array}{l}\text { Source of } \\
\text { Variation }\end{array}$ & $\begin{array}{c}\text { Degrees of } \\
\text { freedom }\end{array}$ & $\begin{array}{r}\text { Sum of } \\
\text { Squares }\end{array}$ & $\begin{array}{r}\text { Mean } \\
\text { Square }\end{array}$ & F ratio & p-value \\
\hline Announcement & 1 & 4,016 & 4,016 & 9.936 & 0.0117 \\
Residual & 9 & 3,638 & 404 & & \\
Total & 10 & 7,654 & & & \\
\hline
\end{tabular}

